\title{
BLEOMYCIN AND SUBSEQUENT ANAESTHESIA: A RETROSPECTIVE STUDY AT VANCOUVER GENERAL HOSPITAL
}

\author{
M.J. Douglas and C.M.L. Coppin
}

ABSTRACT

\begin{abstract}
A retrospective review was made of 20 surgical procedures in 14 patients with testicular carcinoma, previously treated with bleomycin chemotherapy, to evaluate the incidence of postoperative pulmonary complications. Other studies have suggested an increased rate of pulmonary complications, including fatal respiratory failure, when inspired oxygen fraction $\left(\mathrm{F}_{\mathrm{O}_{2}}\right)$ exceeds 0.3 during or after operation. There is a suggestion that bleomycin may sensitize the lungs to the effect of oxygen, leading to oxygen toxicity. This study involved patients whose inspired oxygen fraction ranged from 0.3 to 1.0 and only one non-fatal pulmonary complication occurred. The risks of anaesthesia following bleomycin are discussed with particular reference to possible enhanced oxygen toxicity.
\end{abstract}

A RECEnT ARTICLe by Goldiner and Schweizer ${ }^{1}$ pointed out the potential hazard to patients having long surgical procedures who had previously been treated with bleomycin. They reported on a series of five consecutive young male patients with testicular carcinoma treated with bleomycin, who underwent radical retroperitoneal lymph node dissection or removal of pulmonary metastases, with development of fatal postoperative respiratory failure. The article pointed to the clinical and pathological similarities between oxygen toxicity and the respiratory failure encountered in this group of patients. Their next group of 12 patients received a lower inspired oxygen concentration during operation and in the postoperative period, and particular care was taken with their fluid management. None of these patients had postoperative pulmonary complications.

A review of patients at the Vancouver General Hospital who had received bleomycin and who subsequently had operations was undertaken to see whether any problems had been encountered. The charts of all patients having radical retroperitoneal lymph node dissection in 1977 and 1978 were examined, with respect to prior treatment with bleomycin, $\mathrm{F}_{\mathrm{O}_{2}}$ during operation and

M.J. Douglas, M.D., F.R.C.P.(C) Clinical Assistant Professor, Department of Anaesthesia, Vancouver General Hospital, Vancouver, B.C.

C.M.L. Coppin, M.D., F.R.C.P.(C), D.Phil., Clinical Assistant, Department of Medicine, Vancouver General Hospital, and Staff Physician, Division of Medical Oncology, Cancer Control Agency of British Columbia, Vancouver, B.C.

Communications to: M.J. Douglas, M.D., Department of Anaesthesia, Vancouver General Hospital, 855 12th Avenue West, Vancouver, B.C., V5Z IM9. 449 in the postoperative period, and whether pulmonary problems had followed. This was later expanded to include patients having other major surgical procedures after treatment with bleomycin for testicular carcinoma.

A total of 14 patients who had received bleomycin subsequently underwent 20 surgical procedures, some of which were short in duration, but the majority of the patients (10) had retroperitoneal lymph node dissections. Other procedures included one thoracotomy for wedge resection of metastasis, one craniotomy for removal of a metastasis, one removal of submandibular gland for persistent infection, one cystoscopy and pyelogram, two laparotomies for lysis of adhesions, one debridement of wound, one bronchoscopy and mediastinoscopy, one excision of a groin ulcer, and one thoracoabdominal exploration for tumour. Table I lists the dose of bleomycin given before the operation, the age of each patient, the length of the surgical procedure and $\mathrm{FI}_{\mathrm{O}_{2}}$ during and after operation. In this entire group there was only one case of postoperative pulmonary failure despite a relatively high $\mathrm{F}_{\mathrm{O}_{2}}$ ranging from 0.3 to 1.0 . The case history of the one patient who developed respiratory failure is given below:

\section{CAse Report}

A 64-year-old retired business consultant was seen initially in August, 1978, and underwent radical orchidectomy for embryonal cell carcinoma of the testis with minor teratomatous and seminomatous components. He was then treated with bleomycin, vinblastine and cisplatin for bulky retroperitoneal metastases, the bleomycin

Canad. Anaesth. Soc. J., vol. 27, no. 5, September 1980 
TABLE I

\begin{tabular}{|c|c|c|c|c|c|c|}
\hline \multirow[b]{2}{*}{ Patient } & \multirow[b]{2}{*}{ Age } & \multirow{2}{*}{$\begin{array}{c}\text { Total bleomycin } \\
\text { (units) }\end{array}$} & \multirow[b]{2}{*}{ Operation } & \multirow[b]{2}{*}{$\mathrm{Fi}_{\mathrm{O}_{2}}$} & \multicolumn{2}{|c|}{$\begin{array}{c}\text { Total } \\
\text { duration } \\
\text { anaesthesia }\end{array}$} \\
\hline & & & & & $\mathrm{Hr}$ & Min \\
\hline S.M. & 39 & 300 & radical retroperitoneal lymph node dissection & 0.33 & 5 & 15 \\
\hline H.V.L. & 45 & 165 & radical retroperitoneal lymph node dissection & $0.3^{a}$ & 6 & \\
\hline E.L. & 20 & 300 & removal submandibular gland & $0.3^{a}$ & 1 & 30 \\
\hline \multirow[t]{2}{*}{ R.U. } & 30 & 480 & radical retroperitoneal lymph node dissection & $0.3^{a}$ & 7 & 25 \\
\hline & & 480 & laparotomy, lysis of adhesions & 0.33 & 2 & 35 \\
\hline G.R. & 28 & 140 & thoracotomy, removal metastasis & 0.5 & 3 & 50 \\
\hline \multirow[t]{2}{*}{ B.M. } & 19 & 420 & cystoscopy \& pyelogram & 0.33 & 1 & 12 \\
\hline & & 420 & radical retroperitoneal lymph node dissection & $0.3^{a}$ & 5 & 15 \\
\hline \multirow[t]{2}{*}{ U.F. } & 34 & 300 & radical retroperitoneal lymph node dissection & 0.45 & 8 & 30 \\
\hline & & 300 & laparotomy, lysis of adhesions & 0.3 & 3 & 15 \\
\hline G.D. & 25 & 270 & radical retroperitoneal lymph node dissection & 0.33 & 6 & 35 \\
\hline N.G. & 34 & 180 & craniotomy, removal metastasis & 0.33 & 4 & 40 \\
\hline O.G. & 29 & 150 & radical retroperitoneal lymph node dissection & 0.4 & 7 & 10 \\
\hline \multirow[t]{2}{*}{ B. B. } & 27 & 570 & radical retroperitoneal lymph node dissection & 0.4 & 7 & 40 \\
\hline & & 570 & debridement wound secondary closure & 0.4 & 1 & 20 \\
\hline R.M. & 31 & 300 & radical retroperitoneal lymph node dissection & 0.33 & 4 & 40 \\
\hline \multirow{2}{*}{ F.C. } & 46 & 270 & excision skin ulcer groin & 0.4 & 1 & 40 \\
\hline & & 270 & thoracoabdominal exploration & 0.33 & 3 & 50 \\
\hline \multirow[t]{2}{*}{ I.M. ${ }^{\circ}$} & 64 & 300 & bronchoscopy, mediastinoscopy & 1.0 to 0.5 & 1 & 35 \\
\hline & & 300 & radical retroperitoneal lymph node dissection & 0.24 to 0.26 & 6 & 15 \\
\hline \multirow[t]{2}{*}{ Average } & 34 & $296(125)^{c}$ & & $0.368(0.108)^{c}$ & 4 & 34 \\
\hline & & & & & (2 hrs & $25 \mathrm{~min})$ \\
\hline
\end{tabular}

${ }^{a} \mathrm{No} \mathrm{F}_{\mathrm{O}_{2}}$ stated on the chart. Minimal used in Vancouver General Hospital is 0.3 so this value was taken although in many cases the actual $\mathrm{Fl}_{\mathrm{O}_{2}}$, would be higher.

${ }^{b}$ This is the case report given in the text.

'Standard deviation.

being given weekly as a 30-unit push. In September 1978 the cisplatin was stopped because of renal impairment. At the completion of chemotherapy in October, 1978, he complained of mild exertional dyspnoea and demonstrated a 52 per cent drop in diffusing capacity and lung volume. The chest X-ray showed the development of progressive interstitial changes, compatible with bleomycin toxicity. Bleomycin was discontinued and prednisone was given at 20-45 $\mathrm{mg}$ per day. Dyspnoca and pulmonary function gradually improved. However, the chest $\mathrm{X}$-ray now showed mediastinal widening and probable hilar lymphadenopathy. To exclude recurrent tumour, he underwent bronchoscopy and mediastinoscopy in January, 1979. The procedure lasted one hour and 35 minutes. The $\mathrm{FI}_{\mathrm{O}_{2}}$ during the bronchoscopy was 1.0 and then decreased for the mediastinoscopy to 0.5 . In the recovery room he breathed 70 per cent humidified oxygen. His condition was stable and he was discharged 24 hours later. Two days later he was readmitted because of increasing dyspnoea, now present at rest. On admission, his respiratory rate was $44 / \mathrm{min}$ and he had diffuse bilateral basal and midzone crepitations, more on the right than on the left side. There was no clinical or radiological evidence of left ventricular failure. Arterial blood gases preoperatively breathing room air had been

$\mathrm{Pa}_{\mathrm{O}_{2}} 11.31 \mathrm{kPa}(85 \mathrm{~mm} \mathrm{Hg}) ; \mathrm{Pa}_{\mathrm{CO}_{2}} 4.39 \mathrm{kPa}$ $(33 \mathrm{~mm} \mathrm{Hg}) ; \mathrm{cH}^{+} 37.15 \mathrm{nmol} / \mathrm{l}(\mathrm{pH} \mathrm{7.45})$

and on readmission were

$\mathrm{Pa}_{\mathrm{O}_{2}} 7.05 \mathrm{kPa}(53 \mathrm{~mm} \mathrm{Hg}) ; \mathrm{Pa}_{\mathrm{CO}_{2}} 4.52 \mathrm{kPa}(34 \mathrm{~mm}$ $\mathrm{Hg}) ; \mathrm{cH}^{+} 33.11 \mathrm{nmol} / \mathrm{L}(\mathrm{pH} 7.48)$.

He was treated with 28 per cent oxygen by mask, bed rest, physiotherapy and increased steroids and was discharged unimproved six days later with nasal oxygen to be continued at home.

He was then readmitted in June, 1979, for consideration of radical retroperitoneal lymph node dissection. Pulmonary function had gradually improved during the six months. He now had no complaints of dyspnoea either at rest or on exercise. On examination the chest was clear, but chest X-ray still showed some interstitial changes. Preoperative arterial blood gases had improved on room air with $\mathrm{Pa}_{\mathrm{O}_{2}} 10.11 \mathrm{kPa}(76 \mathrm{~mm}$ $\mathrm{Hg}$ ). Diffusing capacity had also improved from 
37 per cent in December, 1978, to 107 per cent on this admission. The $\mathrm{FT}_{\mathrm{O}_{2}}$ during the subsequent surgical procedure varied between 0.24 and 0.26 and periodic arterial blood gases showed that the $\mathrm{Pa}_{\mathrm{O}_{2}}$ was maintained between 12.1 and $15.16 \mathrm{kPa}$ (91 and $114 \mathrm{~mm} \mathrm{Hg}$ ). The total anaesthetic time for the procedure was six hours and 15 minutes. Fluids were closely monitored and the patient was followed in the intensive care unit for 24 hours postoperatively. He had an uneventful postoperative course and was discharged 10 days later. No tumour was found at either procedure. He remains well.

\section{DisCUSSION}

Bleomycin is a cytotoxic agent of particular usefulness in the treatment of metastatic testicular carcinoma. It has an overall response rate of approximately 40 per cent and, when combined with other agents, can often achieve prolonged remission and possible cure. ${ }^{2}$ Its effectiveness has been well shown in some of the above patients who had demonstrated metastases and who, at subsequent operation had no evidence of active disease.

Approximately five to ten per cent of patients treated with bleomycin develop significant pulmonary complications, ranging from decreased pulmonary function to severe pulmonary fibrosis and death. ${ }^{3}$ The pulmonary toxicity of bleomycin is cumulative, long lasting and appears to be enhanced by increased age, pulmonary radiation therapy and increased dose. It is postulated that the respiratory failure seen postoperatively in patients pretreated with bleomycin results from prolonged oxygen administration, contributing to pulmonary toxicity and subsequent respiratory failure; that is, bleomycin sensitizes the lungs to oxygen toxicity. It appears that if the $\mathrm{FI}_{\mathrm{O}_{2}}$ is maintained below 0.3 this does not occur.'

In 1978, Nygaard ${ }^{4}$ reported a series of patients with oesophageal carcinoma, treated with bleomycin, who later underwent either resection of the oesophagus with replacement or simple exploration and closure. Those who had resection, a longer procedure with greater exposure to oxygen, developed postoperative pulmonary problems and died, while those who had the simpler and shorter procedure of exploration survived the experience.

Since the time of the publication of the article by Goldiner and Schweizer several patients have been operated on at the Vancouver General Hospital and in these cases the $\mathrm{FI}_{\mathrm{O}_{2}}$ and $\mathrm{Pa}_{\mathrm{O}_{2}}$ during operation have been carefully monitored. With the $\mathrm{FI}_{\mathrm{O}_{2}}$ in the 0.22 to 0.25 range, the $\mathrm{Pa}_{\mathrm{O}_{2}}$ has been adequate and in many instances surprisingly good. If the $\mathrm{Pa}_{\mathrm{O}_{2}}$ dropped during operation to less than $9.31 \mathrm{kPa}(70 \mathrm{~mm} \mathrm{Hg})$ the anaesthetist would be obliged to increase the inspired oxygen concentration. Postoperatively, these patients would have to be watched even more closely for signs of developing respiratory failure.

Several points arise from our small series with only one pulmonary complication. Our patient was at particular risk for bleomycin toxicity because of his greater age and because of renal impairment which led to reduced bleomycin clearance. In turn, this may well have put him at particular risk during anaesthesia compared to the other patients who had not shown any clinical or radiographic evidence of bleomycin lung damage, even though his cumulative dose was not higher than the mean of 296 units. The fact that he made slow but remarkable improvement between January and June may be due partly to corticosteroids but might also reflect the restraint in the concentration of oxygen used on his admission with respiratory failure.

Analysis of the first Memorial Sloan-Kettering Cancer Center group ${ }^{5}$ shows that four of their five non-surviving patients had total bleomycin doses of 420-595 units (which is above the manufacturer's recommended total dose of 360 units) and that the fifth had bleomycin treatment stopped after 135 units because of interstitial pneumonitis. Although our sample received a lower average dose, the range is wide and fully overlaps theirs. After the introduction of $\mathrm{F}_{\mathrm{O}_{2}} 0.25$ and closely controlled fluid balance, the Memorial Sloan-Kettering Cancer Center group were able to proceed with major surgery even after 1,100 units of bleomycin or 765 units with interstitial pneumonitis.

In patients who have been treated previously with bleomycin the anaesthetist must exercise caution during operation and in the postoperative period because potentially fatal respiratory failure may develop. This applies particularly to the inspired oxygen concentration and fluid balance. Those patients who have exhibited evidence of previous pulmonary problems are at greater risk for developing the full spectrum of respiratory failure.

\section{REFERENCES}

1. Goldiner, P.L \& Schweizer, O. The hazards of anesthesia and surgery in bleomycin-treated patients. Seminars in Oncology Vol. 6, No.1 (March), 121-124 (1979). 
2. Anderson, R. Testicular germ-cell neoplasms: Recent advances in diagnosis and therapy. Ann. Int. Med. 90: 373-385 (1979).

3. Comis, R.L. Bleomycin pulmonary toxicity, in Carter, S.K., Crooke, S.T., Umezawa, H. (Ed.). Bleomycin: Current Status and New Developments, New York, Academic Press Inc., pp. 279-29l (1978).

4. Nygaard, K., Smith-Erichson, N., Hatle-
vOLL, R., ef al. Pulmonary complications after bleomycin, irradiation and surgery for esophageal cancer. Cancer 4l: 17-22 (1978).

5. Goldiner, P.L. Carlon, G.D., Cvitkovic, E., Schweizer, O. \& Howland, W.S. Factors influencing postoperative morbidity and mortality in patients treated with bleomycin. B.M.J., $1664-1667$ (1978).

\section{RÉSUMÉ}

On a revu les dossiers de 14 patients attei.ts de néoplasie testiculaire dans le but d'établir rincidence des complications post-opératoires survenues à la suite de 20 procédures chirugicales. Tous ces malades avaient été traités au préalable à la bléomycine. Des études antérieures ont suggéré une incidence augmentée de complications post-opératoires, parfois même fatales, lorsque la $\mathrm{FI}_{\mathrm{O}_{2}}$ pre et post-opératoire dépassait $0.3 \mathrm{chez}$ des patients traités à la bléomycine. Cet agent sensibiliserait le poumon à l'oxygène, faisant apparaitre des signes de toxicité à cet agent. Les patients de notre série ont reçu de l'oxygène à des $\mathrm{FI}_{\mathrm{O}_{2}}$ variant de 0.3 à 1.0 et on n'a relevé qu'une seule complication pulmonaire non fatale. On discute des risques anesthésiques des malades traités à la bléomycine, surtout en rapport avec la possibilité d'une susceptibilité augmentée à l'oxygène. 